\title{
O PRINCÍPIO CONTRAMAJORITÁRIO E A UNIÃO HOMOAFETIVA: A FUNDAMENTAL IMPORTÂNCIA DO PODER JUDICIÁRIO NA SOLUÇÃO DE UM DEBATE HODIERNO
}

Renat Nureyev Mendes

ISSUE DOI: $10.21207 / 1983.4225 .247$

\section{RESUMO}

Sabe-se que o "homossexualismo" existiu desde a antiguidade; e, ademais, aqui no Brasil não foi diferente, desde o início da sua história existiam indivíduos com uma orientação sexual diferente e, na época, atípica. Sendo assim, por que a Constituição Federal de 1988, a última CartaMagna brasileira, já no final do século XX, não trouxe em seu texto a possibilidade de uma nova família composta de pessoas do mesmo sexo? Por que foi o poder judiciário, e não o legislativo, que teve, décadas depois, de resolver essa situação de uma forma contramajoritária? Tem-se aqui como escopo maior, a resposta dessas questões. Mas, pretende-se ainda, mostrar como funciona a questão do controle de constitucionalidade, do princípio majoritário e do princípio contramajoritário do Poder Judiciário. Para alcançar esses objetivos, foi feita uma pesquisa bibliográfica, através da utilização de livros e demais referências que tratam do assunto, e de documentos de cunho jurídico. Esse tema, envolvendo os homossexuais, ganhou destaque nessas últimas décadas; a discussão acerca da União Homoafetiva intensificou-se com o advento do terceiro milê- 
nio, e isso foi percebido pelo Judiciário brasileiro que resolveu iniciar um debate a respeito disso para solucionar essa questão, já que não o fez o Poder Legislativo.

Palavras-chave: União Homoafetiva. Poder Judiciário. Princípio Contramajoritário.

\section{INTRODUÇÃO}

Nas últimas décadas, principalmente com o advento do terceiro milênio, as discussões sobre a questão da União Homoafetiva vêm se intensificando, e isso foi percebido pelo Poder Judiciário brasileiro, que foi provocado, estando, desse modo, em conformidade com o princípio da inércia, a iniciar um debate, por meio de seu Supremo Tribunal Federal (STF), em um julgamento conjunto de uma Ação Direta de Inconstitucionalidade (ADI) e de uma Arguição de Descumprimento de Preceito Fundamental (ADPF), para tentar "solucionar" essa questão.

Para isso, o judiciário teve de utilizar um mecanismo próprio que, definitivamente, só pode ser usado por ele mesmo, qual seja, o poder contramajoritário. Esse tem o objetivo de contribuir com o controle de constitucionalidade, mesmo indo "contra" o interesse da maioria dos $\mathrm{Ci}$ dadãos.

Aqui, nesta oportunidade, a fim de cumprir com os propostos escopos, e de modo a facilitar a leitura dos interessados, optou-se por dividir, de maneira didática, este trabalho em três distintos momentos. No primeiro, abordar-se-á o controle de constitucionalidade, além de seu conceito e utilidade; e, outrossim, será mostrado o que é, e como se dá o princípio majoritário.

$\mathrm{Na}$ segunda parte, cumpre discutir o princípio inverso ao citado, isto é, o contramajoritário; além de ilustrar como e por que é feita a utilização desse princípio pelo Poder Judiciário, mostrando como aconteceu a discussão a respeito da União Homoafetiva aqui no Brasil; para se exemplificar a utilização, do princípio citado, pelo Poder Judiciário.

Em um terceiro e último momento, pensou-se em desenvolver o tema "Homossexualidade e União Homoafetiva". Pretende-se, nessa parte, refletir acerca de algumas questões, indiscutivelmente de importância sine qua non, buscando, ademais, as suas respostas na história. 


\section{1}

\section{O CONTROLE DE CONSTITUCIONALIDADE E O PRINCÍPIO MAJORITÁRIO}

No início, os homens viviam, de acordo com Thomas Hobbes, em uma "Guerra de todos contra todos". O medo, nesse momento, reinava, fazendo, assim, com que esses indivíduos (chamados, pelo referido autor, de Selvagens) matassem antes de serem mortos, prevalecendo, nessa época, a "lei do mais forte".

Observando a frase: homo homini lupus ${ }^{236}$, pode-se resumir o que Hobbes pensava acerca da sociedade "pré-contrato social". Del Vecchio $^{237}$ reforça essa ideia quando ele diz que, para o autor do Leviatã $(1651)^{238}$, antes da instituição dos governos, existia uma bellum omnium contra omnes $^{239}$. Assim, nesse estado da natureza, o direito era individual e ilimitado; existindo, portanto, um jus omnium in omnia ${ }^{240}$.

A fim de solucionar essa situação, e também por terem a necessidade de se relacionar socialmente (como dizia, entre outros, Aristóteles e São Tomás de Aquino ${ }^{241}$ ), sendo, portanto, um "Animal Político" ou um "Ser Social", os homens se reuniram para celebrar um famoso e importante acordo: o Contrato Social. Desse, surgiu a Sociedade e o Estado, e com eles, o Direito. Aqui, cada homem abdicou de parte de sua liberdade, com o escopo de ter mais segurança. O Estado, nesse momento, teria de cumprir com suas obrigações (deveres), e buscar o bem comum, já que ele era uma reunião de vontades.

Sobre essa questão, Hobbes coloca que:

A conveniência de todo homem [é] sair desse estado de natureza, mísero e odioso, por causa dos perigos que a contínua guerra leva consigo. Mas isso somente é possível mediante um contrato, que tenha

\footnotetext{
236 “O homem é um lobo para o homem”.

237 DEL VECCHIO, Giorgio. História da Filosofia do Direito. Belo Horizonte: Líder, 2006. p. 25.

238 Thomas Hobbes.

239 "Guerra de todos contra todos".

240 "Direito de todos contra tudo".

${ }^{241}$ Para Aristóteles, "o homem é um animal político [...], isto é, chamado pela sua própria natureza à vida política" (DEL VECCHIO, Giorgio. op.cit., p. 25). São Tomás de Aquino, influenciado por Aristóteles, concorda com este quando diz que "o Estado [...] deriva da natureza social do homem" (DEL VECCHIO, Giorgio. op.cit., p.47).
} 
por conteúdo a renúncia de todos àquela liberdade sem freios própria do estado de natureza. Tal renúncia deve ser inteira, incondicionada, para que, de outra forma, não recaia na anarquia primitiva, em poder do desenfreado egoísmo individual. ${ }^{242}$

Jean Jacques Rousseau vai mais além. Para ele não basta ter havido um momento inicial de legitimidade do Estado; torna-se, necessário, ainda que esse processo de legitimação, da fundação do corpo político, estenda-se também para a máquina política em funcionamento. Assim,

Para que o corpo político se desenvolva, não basta o ato de vontade fundador da associação, é preciso que essa vontade se realize. [...] Se a administração é um órgão importante para o bom funcionamento da máquina política, qualquer forma de governo que venha a adotar terá que submeter-se ao poder soberano do povo. ${ }^{243}$

Percebe-se, portanto, que Rousseau valoriza e defende a supremacia da vontade da maioria. Hoje, ainda é a vontade da maioria que prevalece (Princípio Majoritário); todavia, às vezes, o Poder Judiciário tem que usar de um princípio divergente e contrário (Contramajoritário) para defender a Constituição de seu País, e cumprir a sua função social. Sobre essa função, o judiciário, muitas vezes a faz através de mecanismos presentes nas Constituiçõos Pós-modernas.

"O legislador originário criou mecanismos por meio dos quais se controlam os atos normativos, verificando sua adequação aos preceitos previstos na 'Lei Maior"'244. Sendo assim, podemos, através de uma análise do termo, inclusive, deduzir que o controle de constitucionalidade serve para verificar se as legislações, os fatos sociais e as demais normas estão de acordo (em harmonia), com a constituição, que é a carta magna

${ }^{242}$ DEL VECCHIO, Giorgio. História da filosofia do direito. Belo Horizonte: Líder, 2006. p. 77.

${ }^{243}$ NASCIMENTO, Milton Meira do. Rousseau: da servidão à liberdade. In: WEFFORT, Francisco Correa (org.). Os clássicos da política: volume 1. São Paulo: Ática, 2006. p. 197.

${ }^{244}$ LENZA, Pedro. Direito constitucional esquematizado. São Paulo: Saraiva, 2011. p. 219. 
de um país. Pensando nisso, o Professor Bernardo Gonçalves conceitua-o da seguinte maneira:

O controle de constitucionalidade visa garantir a supremacia e a defesa das normas constitucionais (explícitas ou implícitas) frente a possíveis usurpações, devendo ser entendido como a verificação de compatibilidade (ou adequação) de leis ou atos normativos em relação a uma constituição, no que tange ao preenchimento de requisitos formais e materiais que as leis ou atos normativos devem necessariamente observar. ${ }^{245}$

O Poder Judiciário, além de suas funções jurisdicionais, também partilha de algumas outras funções atípicas, tais como, a de administrar e a de legislar. Santos discorre sobre isso, comentando que:

A grande problemática no que diz respeito às funções atípicas é encontrar os limites para o exercício de tais funções, especialmente em relação ao Poder Judiciário que ao exercer o controle de constitucionalidade das leis e atos normativos do poder público é visto por membros dos demais Poderes como usurpador da função legislativa. ${ }^{246}$

Apesar desse "ciúme" dos outros poderes estatais, o Judiciário deve pensar que o Direito, ainda que não escrito, é o mecanismo responsável pela organização da sociedade; e o controle de constitucionalidade, manejado pelo STF, funciona como mecanismo que garante a supremacia dos direitos fundamentais. E que em algumas situações, como explica Victor Marcel Pinheiro e Virgílio Afonso da Silva, exatamente por ser o guardião da Constituição:

245 FERNANDES, Bernardo Gonçalves. Curso de Direito Constitucional. Rio de Janeiro: Lumen Juris, 2011. p. 901.

246 SANTOS, Bruna Izídio de Castro. O Princípio Contramajoritário como característica do Controle de Constitucionalidade. 2011. 76 f. Monografia apresentada na Faculdade de Direito das faculdades integradas Antônio Eufrásio de Toledo para obtenção de Bacharel em Direito. p. 34. 
o STF exprime a idéia exposta acima de que a ele não é permitido inovar o sistema jurídico, mas apenas afastar aquelas que julgue em desacordo com as normas constitucionais. A partir desta concepção, o Tribunal utiliza em suas decisões as expressões legislador positivo ou legislador negativo para diferenciar estas competências; neste sentido, o Tribunal somente poderia exercer as prerrogativas de um legislador negativo, ou seja, um órgão capaz apenas de afastar do ordenamento jurídico brasileiro as normas inconstitucionais; desta forma, caberia ao poder Legislativo a função de criar normas jurídicas, atuando como legislador positivo. ${ }^{247}$

Nesse sentido, é perceptível que o controle judicial de constitucionalidade é de importância fundamental, pois, ele é uma forma de limitar o Poder Legislativo, pois nenhum Poder (função) estatal é soberano e todos estão sujeitos a algum tipo de controle para que não violem a Lei Maior, que é a Constituição. ${ }^{248}$

$\mathrm{Na}$ democracia o poder emana do povo; nesse sentido, Santos ${ }^{249}$ escreve que "um governo dotado de regime democrático é baseado na vontade da maioria do povo. O povo é soberano e pode exercer o poder direta ou indiretamente".

Scandelai ${ }^{250}$ deixa claro que o Princípio Majoritário é a coluna de uma sociedade democrática, pois esse princípio se trata do "governo da Maioria", ou seja, do povo. Todavia, esse princípio não é absoluto; tem-se que entender que existe uma supremacia da Constituição em detrimento dele.

Levando-se em conta essa questão, do Princípio Majoritário ser o alicerce da democracia, o mais comum de se acontecer é que seja utili-

\footnotetext{
247 SANTOS, Bruna Izídio de Castro. O Princípio contramajoritário como característica do controle de constitucionalidade. 2011. $76 \mathrm{f}$. Monografia apresentada na Faculdade de Direito das faculdades integradas Antônio Eufrásio de Toledo para obtenção de Bacharel em Direito. p. 34.

248 Ibidem.

${ }^{249}$ Idem. p. 48.

250 SCANDELAI, Alice Linares de Oliveira. O princípio contramajoritário como elemento limitador do direito penal do inimigo. 2012. Monografia apresentada na Faculdade de Direito das faculdades integradas Antônio Eufrásio de Toledo para obtenção de Bacharel em Direito.
} 
zado esse Princípio, pois acredita-se que, assim, o Estado Democrático de Direito estará fazendo jus à sua nomenclatura.

Entretanto, como veremos no próximo tópico, é mister que o poder judiciário se utilize, quando necessário, do princípio contramajoritário, para, desse modo, defender a constituição - cumprindo, dessa maneira, a sua função social de guardião que é do Texto Maior, como já mencionado.

\section{O PRINCÍPIO CONTRAMAJORITÁRIO E A PROTEÇÃO À MINORIA}

Entende-se o Princípio contramajoritário como princípio justificador da atuação do Poder Judiciário contrária à vontade da maioria ${ }^{251}$. Ele, portanto, atua contra as maiorias ocasionais em defesa de uma minoria protegida constitucionalmente pelos direitos e garantias fundamentais previstos na Carta-Magna de um País.

Os poderes Legislativo e Executivo, escolhidos pelo povo em sua maioria, representam a população de um determinado território. Pensando nisso, Santos ${ }^{252}$ coloca que "as atividades legislativa e executiva são exercidas pelos representantes diretamente eleitos pelo povo e, por isso, parecem representar a vontade da maioria". Essa vontade "é a que em regra prevalece, porém deve-se observar que uma maioria parlamentar ocasional pode ser na verdade uma minoria dominante". ${ }^{253}$

Em detrimento a esses poderes, o judiciário, que não tem em sua estrutura indivíduos escolhidos pelo povo, e que tem o dever de proteger a Lei Maior, quando o faz, utiliza-se de procedimentos pouco usuais, pois, realiza o controle de constitucionalidade contramajoritariamente, uma vez que os outros dois poderes atuam em nome da maioria.

Logo, o Contramajoritarismo é, de acordo com Vicente Paulo de Almeida ${ }^{254}$, "a atuação do poder judiciário atuando ora como legislador

\footnotetext{
251 SANTOS, Bruna Izídio de Castro. O Princípio contramajoritário como característica do controle de constitucionalidade. 2011. $76 \mathrm{f}$. Monografia apresentada na Faculdade de Direito das faculdades integradas Antônio Eufrásio de Toledo para obtenção de Bacharel em Direito.

${ }^{252}$ Idem. p. 60.

${ }^{253}$ Idem. p. 61.

${ }^{254}$ Idem. p. 60.
} 
negativo, ao invalidar atos e leis dos poderes legislativos ou executivos democraticamente eleitos, ora como legislador positivo - ao interpretar as normas e princípios e lhes atribuírem juízo de valor".

A fim de exemplificar como funciona a utilização, pelo judiciário, desse tão citado princípio, tentaremos mostrar como se deu a solução jurídico-social encontrada para a questão hodierna da União Homoafetiva aqui no Brasil, mostrando quais foram os argumentos utilizados pelo $\mathrm{Su}-$ premo Tribunal Federal (STF) para Legitimar esse direito constitucionalmente previsto.

Sabemos o quão importante é respeitar a Magna Carta de um País. Com o intuito de argumentar para resolver essa questão dos homossexuais no Brasil, o STF aplicou, com efeito, os princípios presentes, tanto na Constituição Federal, quanto nos Tratados Internacionais assinados pela República Federativa do Brasil (sendo, portanto, uma extensão material de nossa Carta Política), ao caso propriamente dito.

Dessa forma,

[a] nossa Constituição da República possui como princípios fundamentais (art. $1^{\circ}$ da $\mathrm{CR} / 88$ ), dentre outros, a cidadania e a dignidade da pessoa humana e, por outro lado, tem por objetivos (art. $3^{\circ}$ da $\mathrm{CR} / 88$ ), entre outros, a construção de uma sociedade livre, justa e solidária, promovendo o bem de todos, sem preconceitos de origem, raça, sexo, cor, idade e quaisquer outras formas de discriminação. ${ }^{255}$

O discurso dos tratados (Declaração Universal dos Direitos Humanos; Pacto São José da Costa Rica; entre outros...) segue os mesmos preceitos da nossa Constituição, dizendo, por exemplo, que todos são livres, iguais em dignidade e direitos, que devem ter uns para com os outros o espírito de fraternidade, além do respeito, tão defendido por todos esses documentos jurídicos.

255 FERREIRA, Renato Ângelo Salvador. A importância do papel contramajoritário assumido pelo Supremo Tribunal Federal no julgamento da Ação Direta de Inconstitucionalidade (ADI) 4277 e da Arguição de Descumprimento de Preceito Fundamental (ADPF) 132. MPMG Jurídico, Belo Horizonte, n.24, p.15-18, set./dez., 2012. p. 15. 
No mesmo sentido, Renato Ângelo Salvador Ferreira ${ }^{256}$ diz que:

O Supremo Tribunal Federal (STF) observou não só o disposto na Constituição de 1988, como também o previsto nos Tratados Internacionais de Direitos Humanos, e, sobretudo, o fez com expresso poder contramajoritário, atuando na proteção das minorias contra imposições discriminatórias e desarrazoadas das maiorias, interpretando e aplicando o ordenamento jurídico em favor dos vulneráveis homoafetivos.

No julgamento da ADI 4277/DF e da ADPF 132/RJ 257 , "ao decidir que a união estável homoafetiva tem regime jurídico de entidade familiar, o STF assegurou a uma parcela minoritária da população o direito de não se esconder sob o manto da vergonha, de não se submeter à maioria". ${ }^{258}$

Destarte, "a pesquisa realizada pela Fundação Perseu Abramo e pela Fundação Rosa Luxemburg traz um dado surpreendente: 99\% dos brasileiros têm algum tipo de preconceito, ainda que velado, contra homossexuais". 259

Outrossim, é importante destacar, nesse sentido, que $55 \%{ }^{260}$ da População brasileira foi contra a decisão do STF, de acordo com uma

\footnotetext{
256 FERREIRA, Renato Ângelo Salvador. A importância do papel contramajoritário assumido pelo Supremo Tribunal Federal no julgamento da Ação Direta de Inconstitucionalidade (ADI) 4277 e da Arguição de Descumprimento de Preceito Fundamental (ADPF) 132. MPMG Jurídico, Belo Horizonte, n.24, p.15-18, set./dez., 2012. p. 15.

${ }^{257}$ Foi no julgamento conjunto da Ação Direta de Inconstitucionalidade (ADI) 4277 e da Arguição de Descumprimento de Preceito Fundamental (ADPF) 132, que se discutiu se era possível equiparar a união entre pessoas do mesmo sexo à entidade familiar, prevista no artigo 1.723 do Código Civil (CC).

${ }^{258}$ FERREIRA, Renato Ângelo Salvador. A importância do papel contramajoritário assumido pelo Supremo Tribunal Federal no julgamento da Ação Direta de Inconstitucionalidade (ADI) 4277 e da Arguição de Descumprimento de Preceito Fundamental (ADPF) 132. MPMG Jurídico, Belo Horizonte, n.24, p.15-18, set./dez., 2012. p. 16.

259 DIAS, Maria Berenice. Legislação brasileira e homofobia. In: VENTURI, Gustavo; BOKANy, Vilma. Diversidade sexual e homofobia no Brasil. São Paulo: Editora Fundação Perseu Abramo, 2011. p. 163.

${ }^{260}$ A margem de erro é de dois pontos percentuais para mais ou para menos.
} 
pesquisa feita pelo Ibope Inteligência, entre os dias 14 e 18 de Julho de 2011, como escreve Reinaldo Azevedo, em seu Blog ${ }^{261}$. Nessa ocasião, foram entrevistados, de modo pessoal, dois mil brasileiros de todas as regiões, distribuídos por idade, sexo e classe de consumo. Apesar disso (desses dados), o Supremo Tribunal Federal não se intimidou e manteve a sua decisão, como deveria ser feito.

Inspirados na Declaração de Virgínia de 12 de junho de 1776, que continha em seu artigo primeiro a expressão Felicidade como direito dos indivíduos, os juristas e jurisconsultos pós-modernos consideram muito esse direito, em especial. Tanto é que, Renato Ferreira, ao comentar a decisão do Judiciário brasileiro em relação a essa questão, observa, com efeito, que "foi uma demonstração fático-jurídica de implementação do princípio da isonomia na realidade social e jurídica brasileira, garantindo a implementação de direitos fundamentais em favor de um grupo de pessoas humanas que também tem o direito de ser feliz"262. E foi pensando nisso que o judiciário brasileiro teve que contrariar a maioria, para buscar justiça para essas pessoas, que, como já citado, também têm o direito de serem felizes.

\section{A HOMOSSEXUALIDADE E A UNIÃO HOMOAFETIVA}

Álvaro Ricardo de Souza $\mathrm{Cruz}^{263}$ define, primariamente, o Homossexual como aquele que mantém, com um parceiro de mesmo sexo, relações sexuais ${ }^{264}$. Todavia, esse autor, estribado nas ideias de Rivera (apud CRUZ), tenta mostrar que, a esse conceito, podem ser adicionados

\footnotetext{
261 AZEVEDO, Reinaldo. União Civil dos Homossexuais contrariam 55\% dos brasileiros. Disponível em: < http://veja.abril.com.br/blog/reinaldo/geral/uniao-civil-dehomossexuais-contraria-55-dos-brasileiros-revela-pesquisa/ $>$. Acesso em: 15 de Abril de 2013.

${ }^{262}$ FERREIRA, Renato Ângelo Salvador. A importância do papel contramajoritário assumido pelo Supremo Tribunal Federal no julgamento da Ação Direta de Inconstitucionalidade (ADI) 4277 e da Arguição de Descumprimento de Preceito Fundamental (ADPF) 132. MPMG Jurídico, Belo Horizonte, n.24, p.15-18, set./dez., 2012. p. 16.

${ }^{263}$ CRUZ, Álvaro Ricardo de Souza. O Direito à Diferença: as ações afirmativas como mecanismo de inclusão social e mulheres, negros, homossexuais e portadores de deficiência. Belo Horizonte: Del Rey, 2005.

264 Aqui, enxergar-se-á o Homossexual como aquele que sente atração por alguém de mesmo sexo que ele, e com este deseja relacionar-se.
} 
outros elementos, tais como as fantasias eróticas e os beijos e abraços e demais carícias. Ou seja, esses elementos também contribuem na identificação e conceituação de um Homossexual.

Sabe-se que desde o início dos tempos, como apregoa estudiosos da história antiga, existiu indivíduos que se "interessavam" por pessoas do mesmo sexo que eles próprios. Os homens gregos, por exemplo, viam as suas mulheres como um "instrumento" para procriação, apenas. Amar mesmo era algo que acontecia entre os homens. E, na História do Brasil, não foi diferente. Desde o século XVI (ou mesmo antes disso, por parte dos índios, como querem alguns autores) há relatos de envolvimento entre pessoas de mesmo sexo. Sob tal alicerce, pode-se fazer uma indagação específica: sendo indubitável a existência de homossexuais e de suas relações homoafetivas em toda a história brasileira, por que a Constituição Cidadã de 1988, já no final do Século XX, não trouxe em seu texto algo que contemplasse esse grupo social em questão? Por que essa intervenção teve de ser feita pelo Poder Judiciário, e não pelo Poder Legislativo (inclusive, pelo Constituinte Originário)?

As possíveis respostas para essas questões podem ser buscadas na história. "A liberdade sexual na atualidade é vista com absoluta intolerância, escárnio e desprezo pela sociedade" ${ }^{265}$. E isso se dá por causa de alguns antecedentes históricos. Sempre houve uma condenação, por parte da Igreja, dessas práticas homossexuais, e isso contribuiu para que se tentasse impedi-las de qualquer jeito. Até a Ciência, no século XIX, entrou nessa, tentando encontrar um modo de condenar o Homossexualismo. Tanto é que os Professores Edson Pires da Fonseca e Paulo Hermano Soares Ribeiro discorrem sobre isso dizendo:

Até mesmo a ciência médica, eventualmente subjugada pela ética religiosa, sugeriu por longo tempo que a homossexualidade fosse uma patologia, daí utilizar o sufixo 'ismo' que denota condição patológica, e se referir ao relacionamento entre pessoas do mesmo sexo como homossexualismo. Somente na décima revisão da classificação internacional de Doenças e Problemas Relacionados

\footnotetext{
${ }^{265}$ CRUZ, Álvaro Ricardo de Souza. O Direito à diferença: as ações afirmativas como mecanismo de inclusão social e mulheres, negros, homossexuais e portadores de deficiência. Belo Horizonte: Del Rey, 2005. p. 76.
} 
à Saúde (CID), da Organização Mundial de Saúde, houve exclusão do Homossexualismo como doença. ${ }^{266}$

Ou seja, "de fato, a homoafetividade foi pensada oficialmente como doença até 1993, quando a Organização Mundial da Saúde deixou de tratá-la como desvio ou transtorno sexual". ${ }^{267}$

Com isso, percebe-se que o Constituinte Originário dificilmente trataria, na Constituição, sobre a temática do Homossexualismo, pois a homoafetividade era tratada como doença até 1993, cinco anos após a nossa Carta-Magna entrar em vigor. Mesmo assim, cabe, nesse contexto, a pergunta: e de 1993 até $2011^{268}$, por que o legislador não tomou providências? Bem, Pires e Ribeiro ${ }^{269}$ entendem que "sua invisibilidade no sistema jurídico positivado apontava (e no Brasil ainda aponta) para uma cegueira de conveniência, sem jamais comprometer-lhe a existência e o significado".

Maria Berenice Dias acredita que o número espantoso, já supracitado, em que quase cem por cento dos brasileiros têm algum tipo de preconceito, ilustra bem a situação e contribui para compreender o silêncio do legislador. Para ela, "a resistência em aprovar qualquer proposta de emenda constitucional ou projeto de lei que assegure direitos e resguarde as uniões homoafetivas é para lá de injustificável, e isso evidencia uma postura discriminatória e preconceituosa". ${ }^{270}$

A Ex-Desembargadora, Maria Berenice, entende que:

A omissão covarde do legislador infraconstitucional de assegurar direito aos homossexuais e reconhecer

266 RIBEIRO, Paulo Hermano Soares; FONSECA, Edson Pires da. Casamento e Divórcio na Perspectiva Civil Constitucional. Leme: J. H. Mizuno, 2012. p. 75.

267 RODRIGUES, Rodrigo Cavalheiro. Proposta de Classificação Jurídica da União Homoafetiva e seu reconhecimento familiar. In: Revista Brasileira de Estudos Jurídicos. Vol. 3, n. 2. p. 61-74. Montes Claros (MG): Editora Fundação Santo Agostinho, 2008. p. 63.

${ }^{268}$ Ano em que foi julgado a ADI 4277/DF e a ADPF 132/RJ.

269 RIBEIRO, Paulo Hermano Soares; FONSECA, Edson Pires da. Casamento e Divórcio na Perspectiva Civil Constitucional. Leme: J. H. Mizuno, 2012. p. 76.

${ }^{270}$ DIAS, Maria Berenice. Legislação brasileira e homofobia. In: VENTURI, Gustavo; BOKANy, Vilma. Diversidade sexual e homofobia no Brasil. São Paulo: Editora Fundação Perseu Abramo, 2011. p. 163. 
seus relacionamentos, ao invés de sinalizar neutralidade, encobre grande preconceito. $\mathrm{O}$ receio de ser rotulado de homossexual, o medo de desagradar o eleitorado e comprometer sua reeleição inibe a aprovação de qualquer norma que assegure direitos à parcela minoritária da população alvo de discriminação. ${ }^{271}$

Em 2011, o STF tratou dessa questão, como já citado em tópico anterior, reconhecendo a União Estável Homoafetiva no Brasil. Mas, a pergunta que se faz é: como ficará, daqui para frente? Os Casais homoafetivos ficaram satisfeitos? Do jeito que está, para esses Casais, ficou melhor do que antes; todavia, eles querem mais, querem a possibilidade de se casar e, por que não, de adotarem filhos, visto que, agora, são reconhecidos como uma família ou, pelo menos, uma entidade familiar.

Nesse diapasão, foi o poder judiciário que solucionou essa questão mesmo sendo do "poder legislativo a obrigação de resguardar o direito de todos os cidadãos, principalmente de quem se encontra em situação de vulnerabilidade" ${ }^{272}$, que é o caso dos homossexuais.
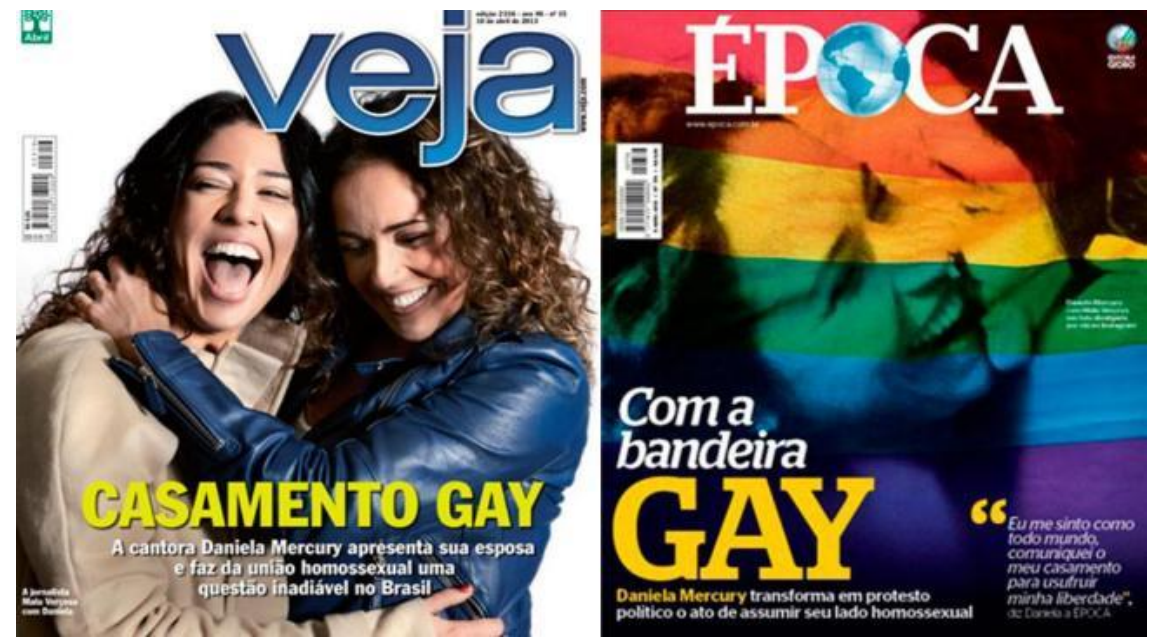

${ }^{271}$ Idem. p. 168.

272 DIAS, Maria Berenice. Legislação brasileira e homofobia. In: VENTURI, Gustavo; BOKANy, Vilma. Diversidade sexual e homofobia no Brasil. São Paulo: Editora Fundação Perseu Abramo, 2011. p. 168. 
Figura 1: Capas das revistas: Veja e Época do mês de Abril do ano de $2013^{273}$.

Sobre esse assunto, a questão que foi colocada em pauta nos últimos tempos pelos meios de comunicação, foi o fato de Daniela Mercury, cantora baiana, famosa pela sua música, assumir (ou comunicar, que é como ela prefere) um relacionamento gay com Malu Verçosa, jornalista. Segundo Adoniran Peres, Correspondente do The Christian Post $t^{274}$, esse fato foi valorizado por dois dos principais veículos de comunicação impressa da nação, quais sejam, os periódicos: Veja e Época (vide a figura 1), que, já nas capas, abordaram o assunto, impactante que foi.

Acredita-se que esse fato (o "namoro" homoafetivo da cantora com a jornalista), com a contribuição da mídia, irá proporcionar uma grande força política para a luta dos casais homoafetivos pelo reconhecimento jurídico-social. Ambas as revistas tratam dessa questão como inadiável, depois do acontecido. E agora, Brasil? Como resolver essa questão? Será que o Princípio Contramajoritário do Poder Judiciário terá de ser acionado mais uma vez? Ou os Legisladores irão tomar a frente para a solução dessa questão? Essas perguntas, que ainda não podem ser respondidas, ficarão, portanto, no plano dos debates sociais.

\section{CONSIDERAÇÕES FINAIS}

Ao longo desse trabalho procurou-se demonstrar, através de uma pesquisa sobre o princípio contramajoritário, que ele se faz presente no direito brasileiro e deve, sempre que necessário, ser acionado pelo Poder Judiciário.

Com a pretensão de ilustrar como o referido princípio é utilizado, buscou-se demonstrar a atuação do Supremo Tribunal Federal (STF) no julgamento conjunto da Ação Direta de Inconstitucionalidade (ADI) 4277 e da Arguição de Descumprimento de Preceito Fundamental (ADPF) 132, que tratava sobre a questão da União Homoafetiva.

\footnotetext{
273 Disponível em: <http://atarde.uol.com.br/chamegente/materias/1495163-revistasnacionais-destacam-casamento-gay-de-daniela-mercury $>$.

274 The Christian Post é uma famosa fonte de notícias cristãs nos Estados Unidos e na maior parte do mundo. Possui cobertura nacional e internacional de eventos.
} 
homossexuais-contraria-55-dos-brasileiros-revela-pesquisa/> .

Acesso em: 15 de Abril de 2013.

. Daniela Mercury tem "esposa" e também

criticou Feliciano. Então tá. Disponível em: < http://veja.abril.com.br/blog/reinaldo/geral/daniela-mercury-temesposa-e-tambem-criticou-feliciano-entao-ta/ >. Acesso em: 15 de Abril de 2013.

BARRAL, Welber Oliveira. Metodologia da Pesquisa Jurídica. Belo Horizonte: Del Rey, 2010.

BRASIL. Constituição (1988). Constituição [da] Republica Federativa do Brasil. Brasília, DF: Senado Federal.

CARELLI, Gabriela. A Revelação. Revista Veja, São Paulo, Ed. Abril, p. 68-78, Abr. 2013.

CRUZ, Álvaro Ricardo de Souza. O Direito à Diferença: as ações afirmativas como mecanismo de inclusão social e mulheres, negros, homossexuais e portadores de deficiência. Belo Horizonte: Del Rey, 2005.

DALLARI, Dalmo. Elementos de teoria geral do Estado. São Paulo: Saraiva, 2011.

DEL VECCHIO, Giorgio. História da Filosofia do Direito. Belo Horizonte: Ed. Líder, 2006.

DIAS, Maria Berenice. Legislação brasileira e homofobia. In: VENTURI, Gustavo; BOKANy, Vilma. Diversidade sexual e homofobia no Brasil. São Paulo: Editora Fundação Perseu Abramo, 2011.

FERNANDES, Bernardo Gonçalves. Curso de Direito Constitucional. Rio de Janeiro: Lumen Juris, 2011.

FERREIRA, Renato Ângelo Salvador. A importância do papel contramajoritário assumido pelo Supremo Tribunal Federal no julgamento da Ação Direta de Inconstitucionalidade (ADI) 4277 e da Arguição de Descumprimento de Preceito Fundamental (ADPF) 132. MPMG Jurídico, Belo Horizonte, n.24, p.15-18, set./dez., 2012.

LENZA, Pedro. Direito Constitucional Esquematizado. São Paulo: Saraiva, 2011.

NASCIMENTO, Milton Meira do. Rousseau: da servidão à liberdade. In: WEFFORT, Francisco Correa (org.). Os clássicos da Política: volume 1. São Paulo: Ática, 2006.

OSHIMA, Flávia Yuri et al. Depois daquele beijo. Época, São Paulo, Ed. Globo, p. 72-79, Abr. 2013. 
PERES, Adoniran. Com Daniela Mercury na capa, Veja e Época trazem discussão sobre casamento gay. Disponível em: $<$ http://portugues.christianpost.com/news/com-daniela-mercury-nacapa-veja-e-epoca-trazem-discussao-sobre-casamento-gay15676/>. Acesso em: 15 de Abril de 2013.

RIBEIRO, Paulo Hermano Soares; FONSECA, Edson Pires da. Casamento e Divórcio na Perspectiva Civil Constitucional. Leme: J. H. Mizuno, 2012.

RODRIGUES, Rodrigo Cavalheiro. Proposta de Classificação Jurídica da União Homoafetiva e seu reconhecimento familiar. In: Revista Brasileira de Estudos Jurídicos. Vol. 3, n. 2. p. 61-74. Montes Claros (MG): Editora Fundação Santo Agostinho, 2008.

SANTOS, Bruna Izídio de Castro. O Princípio Contramajoritário como característica do Controle de Constitucionalidade. 2011. 76 f. Monografia apresentada na Faculdade de Direito das faculdades integradas Antônio Eufrásio de Toledo para obtenção de Bacharel em Direito.

SCANDELAI, Alice Linares de Oliveira. O Princípio Contramajoritário como elemento limitador do Direito Penal do Inimigo. 2012. Monografia apresentada na Faculdade de Direito das faculdades integradas Antônio Eufrásio de Toledo para obtenção de Bacharel em Direito. 
